UDK 630*4:502.4(497.5)(210.7 Veliki Brijun)

\title{
ZDRAVSTVENO STANJE ŠUMSKE VEGETACIJE OTOKA VELIKI BRIJUN, NACIONALNI PARK BRIJUNI, HRVATSKA*
}

\section{Health Condition of the Forest Vegetation on the Island of Veliki Brijun, National Park Brijuni, Croatia}

\author{
Sanja Novak Agbaba ${ }^{1}$, Nevenka Ćelepirović ${ }^{1}$
}

\begin{abstract}
National Park "Brijuni" is located in the north part of the Adriatic Sea, close to the west coast of the Istria Peninsula. On the island Veliki Brijun, the largest island in the National Park Brijuni, preliminary investigation of the health condition of the forest vegetation was carried out. The symptoms of the diseases and the damages were recorded and their causative agents were determined. The health condition of the forest vegetation was observed at eight locations. The samples of plant material and fungi were collected and brought to the laboratory for analysis. The preliminary health condition survey showed the following damages and deceases: leaf spots on Quercus ilex and Laurus nobilis, death of branches and tree tops in Cupressus sempervirens and Calocedrus decurens, foliar disease and insects in bark and wood on Pinus halepensis and Pinus brutia, stem damages on different tree species caused by game, and damage of Quercus ilex stands caused by fungus Phellinus sp.
\end{abstract}

Key words: National park Brijuni, Mediterranean forest vegetation, health condition, Quercus ilex, Phellinus sp.

\section{Izvod}

Nacionalni park Brijuni smješten je u sjevernom dijelu Jadranskog mora uz zapadnu obalu poluotoka Istre. Na najvećem otoku, Veliki Brijun, provedeno je preliminarno istraživanje zdravstvenog stanja šumske vegetacije. Zabilježeni su simptomi bolesti i oštećenja, te determinirani njihovi uzročnici. Zdravstveno stanje šumske vegetacije je pregledano na osam lokacija. Skupljeni su uzorci biljnog materijala i gljiva za laboratorijsku analizu. Preliminarni zdravstveni pregled pokazao je sljedeće bolesti i oštećenja: pjegavost lišća Quercus ilex i Laurus nobilis, sušenje pojedinih grana i vrhova stabala Cupressus sempervirens i Calocedrus decurens, osip iglica bora i simptomi napada ksilofagnih kukaca na Pinus halepensis i Pinus brutia,

\footnotetext{
* Rad prezentiran na međunarodnoj naučnoj Konferenciji "Šumarska nauka između ekonomije i zahtjeva društva", povodom 60. godišnjice Šumarskog fakulta Univerziteta u Sarajevu, Sarajevo, hotel "Hollywood" 8 - 10.10.2008. godine

1 Šumarski institut, Jastrebarsko, Hrvatska - Forest Research Institute Jastrebarsko, Croatia
} 
oštećenja od divljači na različitim vrstama drveća i oštećenja sastojina Quercus ilex uzrokovana gljivom Phellinus sp.

Ključne riječi: Nacionalni park "Brijuni", mediteranska šumska vegetacija, zdravstveno stanje, Quercus ilex, Phellinus sp.

\section{UVOD - Introduction}

Brijunska skupina otoka smještena je u sjevernom dijelu Jadranskog mora uz zapadnu obalu poluotoka Istre, nasuprot gradića Fažane. Nacionalnim parkom proglašen je 1983. godine. Najveći otoci u skupini od 14 otoka su Veliki Brijun $\left(7 \mathrm{~km}^{2}\right)$ i Mali Brijun $\left(1,7 \mathrm{~km}^{2}\right)$. Austrijski industrijalac, tadašnji vlasnik Brijuna, Paul Kupelwieser je u 19. stoljeću malarično otočje Brijuni preuredio u lječilište i ljetovalište. Uključio je Heinricha Hermanna Roberta Kocha, njemačkog liječnika i bakteriologa za zadatkom da ukloni malariju na otocima (FATOVIĆ - FERENČıć, 2006). Zaposlio je labinskog šumara Alojza Čufara za uređenje šumske i parkovne vegetacije na otočju.

Vegetaciju Nacionalnog parka "Brijuni" čine: šuma uređajnog razreda hrasta crnike (179 ha), makija (190 ha), crnogorica (18 ha), parkovi (117 ha), travnjaci (124 ha). Najznačajnije su tipične šume hrasta crnike (Orno-quercetum ilicis, 68 ha), šuma lovora i crnike (Orno-quercetum ilicis laurosum 48 ha). U zajednici crnike zastupljeni su autohtoni mediteranski florni elementi: zelenika, planika, mirta, smrdljika, tršlja i crni jasen. Osim domaćih vrsta, unesene su i brojne strane vrste: pinija, alepski bor, brucijski bor, crni bor, atlanski, himalajski i libanonski cedrovi, grčka i španjolska jela, sekvoja, čempresi i eukaliptusi. Na Velikom Brijunu početkom 20. st. unesene su strane vrste divljači: jelen aksis (Aksis aksis), jelen lopatar (Dama dama) i muflon (Ovis musimon). Divljač se dobro prilagodila staništu zahvaljujući idealnim mikroklimatskim uvjetima (www.brijuni.com). Na otoku Veliki Brijun provedena su istraživanja zdravstvenog stanja šumskih vrsta drveća. Determinirani su štetni organizmi, gljive i kukci (GLAVAŠ, 1999; HARTMAN I SUR., 2007; RIFFLE, PETERSON, 1986; ZUBRIK I SUR., 2008).

\section{MATERIJALI I METODE RADA - Materials and methods}

Terenski obilazak šumskog područja obavljen je na otoku Veliki Brijun. Sakupljeni su uzorci bolesti i štetnika za laboratorijsku analizu. Pregled zdravstvenog stanja glavnih vrsta šumskog drveća proveden je na osam lokaliteta (slika 1): Hotel «Neptun», Borov Vršić, Straža, Planikovac, Ciprovac, Crnikovac, Stari vinogradi i Mrtvi vrh. 


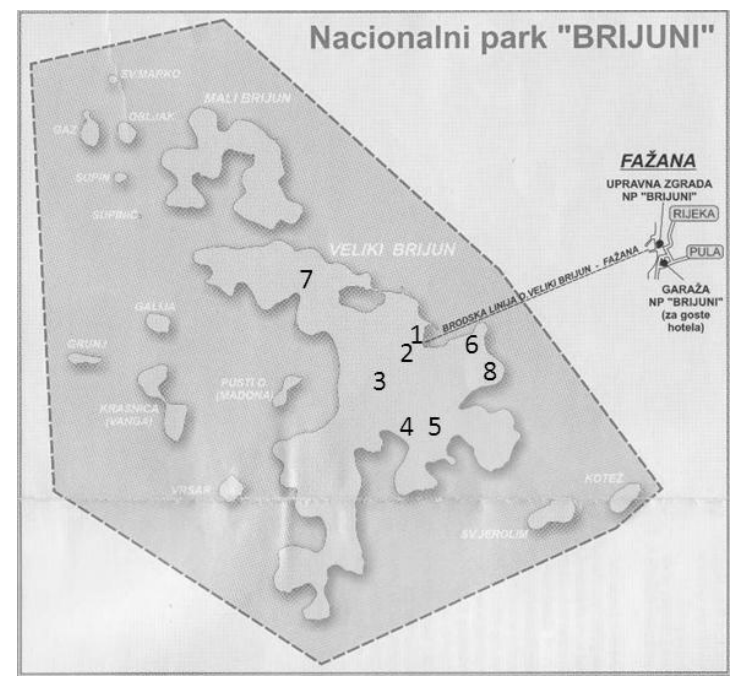

Slika 1. Lokaliteti na otoku Veliki Brijun: 1. Hotel «Neptun», 2. Borov Vršić, 3. Straža, 4. Planikovac, 5. Ciprovac, 6. Crnikovac, 7. Stari vinogradi, 8. Mrtvi vrh.

Figure 1. Locations on the island of Veliki Brijun: 1. Hotel «Neptun», 2. Borov Vršić, 3.

Straža, 4. Planikovac, 5. Ciprovac, 6. Crnikovac, 7. Stari vinogradi, 8. Mrtvi vrh.

Vrste drveća koje su uočene na izabranim lokalitetima prikazane su u zabeli 1.

\begin{tabular}{|c|c|}
\hline 1. Hotel „Neptun“ & $\begin{array}{l}\text { Quercus ilex L. - crnika } \\
\text { Pseudotsuga douglasii Mirb. Franco. - zelena duglazija } \\
\text { Calocedrus decurens (Torr.) Florin. - kalifornijski libocedar } \\
\text { Laurus nobilis L. - lovor }\end{array}$ \\
\hline 2. Borov Vršić & $\begin{array}{l}\text { Pinus halepensis Mill. - alepski bor } \\
\text { Pinus brutia Ten. - brucijski bor }\end{array}$ \\
\hline 3. Straža & Cupressus sempervirens L. - obični čempres \\
\hline 4. Planikovac & $\begin{array}{l}\text { Quercus ilex L.- crnika } \\
\text { Cupressus sempervirens L. - obični čempres }\end{array}$ \\
\hline 5. Ciprovac & $\begin{array}{l}\text { Quercus ilex L. - crnika } \\
\text { Fraxinus ornus L. - crni jasen } \\
\text { Laurus nobilis L. - lovor } \\
\text { Phillyrea latifolia } \text { L. - zelenika } \\
\text { Arbutus unedo } \quad \text { L. - obična planika }\end{array}$ \\
\hline 6. Crnikovac & $\begin{array}{l}\text { Quercus ilex L. - crnika } \\
\text { Laurus nobilis L. - lovor }\end{array}$ \\
\hline 7. Stari vinogradi & Quercus ilex L- - crnika \\
\hline 8. Mrtvi vrh & Pinus halepensis Mill. - alepski bor \\
\hline
\end{tabular}

Tabela 1. Vrste drveća po lokalitetima

Table 1. Tree species at eight localities 


\section{REZULTATI ISTRAŽIVANJA I DISKUSIJA - The results of the study and discussion}

\section{LOKALITET BR. 1 - HOTEL NEPTUN}

Na hrastu crniki primijećena je gljivična bolest lišća (svjetlosmeđe pjege) čiji uzročnik je gljiva Phyllosticta quercus ilicis Sacc (slika 2.). Zaraza je srednje jakog intenziteta. Na donjoj strani lista uočene su smeđe baršunaste pustule izazvane gljivom Cronartium quercuum (Berk.) Miyabe ex Shirai malog intenziteta zaraze, te oštećenja na listu u vidu gala, koje uzrokuje grinja Aceria ilicis G. Canestrini, malog intenziteta zaraze. Na starim stablima crnike uočene su trule grane u krošnji. Trulež je uzrokovana gljivama truležnicama. Na duglaziji je uočeno žućenje, smeđenje i opadanje vršnih iglica, te gole vršne grančice. Uzročnik su lisne uši Adelges cooleyi Gillette. Intenzitet oštećenja je srednje jak do jak. Na kalifornijskom libocedru uočeni su simptomi žućenja listića i sušenja grančica srednje do jakog intenziteta. Nekoliko stabala imaju suhi vrh ili suhu deblju granu u krošnji. Uzročnici su gljive Cronartium quercuum (Berk.) Miyabe ex Shirai i Kabatina thujae Schneider et von Arx. Na lišću skupine mlađih stabala lovora uočene su pjege malog intenziteta. Uzročnik je gljiva Phyllosticta quercus ilicis Sacc.

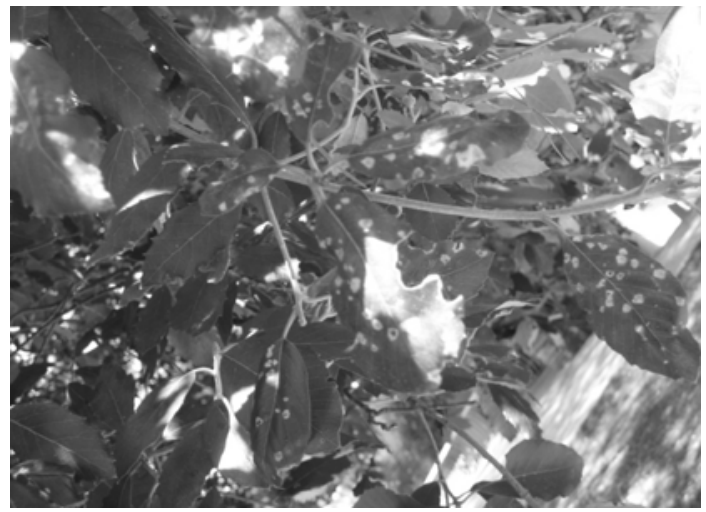

Slika 2. Pjegavost lišća hrasta crnike

Figure 2. Phyllosticta quercus ilicis Sacc on Quercus ilex L.

\section{LOKALITET BR. 2 - BOROV VRŠIĆ}

Na ovom lokalitetu najzastupljeniji su alepski bor i brucijski bor. Krošnje su prorijeđene. U krošnji je prisutno žućenje, smeđenje i opadanje iglica srednje jakog do jakog intenziteta. Te simptome bolesti uzrokuju gljive Lophodermium pinastri (Schrad. ex Hook) Chev., Lophodermium seditiosum Minter,Staly et Millar, Mycospherella pini Rostrup ap. Munk i Thyriopsis halepensis (Cooke) Thess. et Syd. Na pojedinim stablima uočeno je smoljenje iz oštećenja na deblu, odlupljivanje kore i hodnici između kore i bjelike. Uzročnici su kukci: Ips sexdentatus Boern., Tomicus 
spp.; Phaenopis cyanea F. Na nekim deblima uočene su uzdužne ozljede od baze do $1,5 \mathrm{~m}$ visine iz kojih obilno smoli. Na trulom dijelu debla uočeni su veliki mravi (iz porodice Formicidae). U vrhu krošnje alepskog bora vide se slomljene grane. Oštećenja su nastala vjetrolomom iz 2006. godine i predstavljaju ulazna mjesta za štetne biotičke čimbenike (gljive i kukce).

\section{LOKALITET BR. 3 - STRAŽA}

Na ovom lokalitetu nalazi se grupa stabala čempresa. Na donjem dijelu debla vide se jaka oštećenja kore (ozljede i oljuštena kora) djelovanjem divljači. U krošnji su prisutne suhe deblje i tanje grane te suhi vrhovi stabala. Nekoliko stabala je potpuno suho. Uzročnik bolesti raka kore je gljiva Seiridium cardinale (Wagner) Sutton et Gibson (slika 3). Na pojedinim stablima crnike vidljive su suhe vršne grane u krošnji od hrastovog prstenara (Coraebus bifasciatus Vilers).

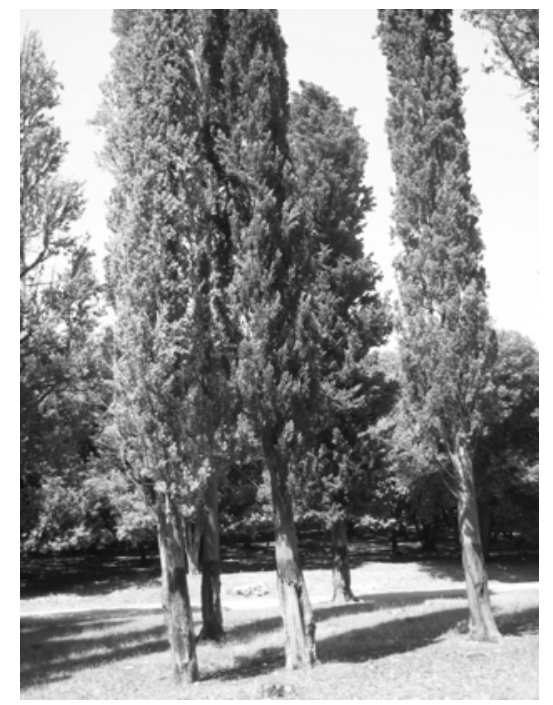

Slika 3. Rak kore čempresa uzrokovan gljivom Seiridium cardinale

Figure 3. Cortical cancer caused by fungus Seiridium cardinale

\section{LOKALITET BR. 4 - PLANIKOVAC}

To je područje na kojem prevladava hrast crnika. Prisutne su štete od hrastova prstenara (Coraebus bifasciatus Vilers) manjeg intenziteta, gljivično oboljenje lišća u vidu svijetlosmeđih pjega uzročnika Phyllosticta illicis Sacc. malog do srednje jakog intenziteta. Na deblu se vide ozljede od divljači na kojima se razvija trulež. Na mnogim stablima crnike, na deblu kao i na donjoj strani debljih grana u krošnji, obilno se javlja gljiva Phellinus sp. (slika 4) duguljastog, poleglog plodišta. Na stablima 
čempresa vide se ozljede od divljači, sušenje dijelova stabala te cijelih stabala od raka kore (Seiridium cardinale-Wagner- Sutton et Gibson).

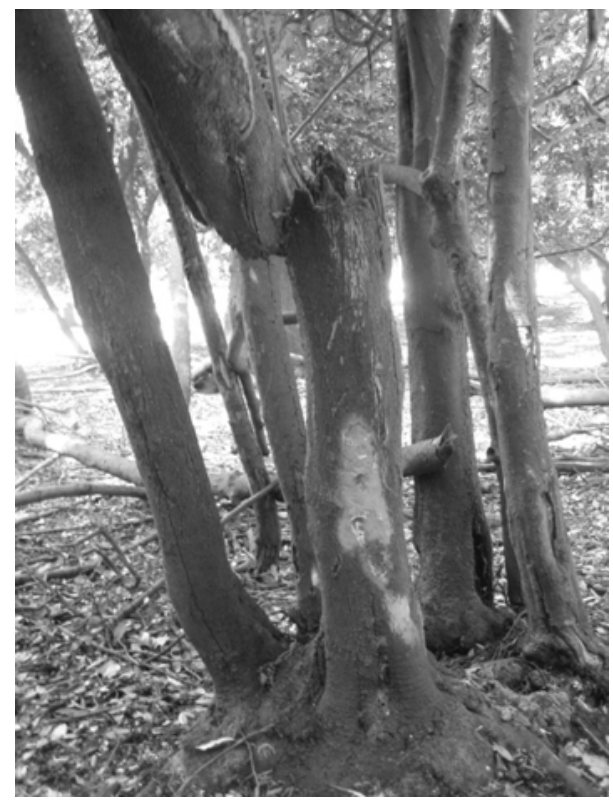

Slika 4. Trulež stabla uzrokovana gljivom Phellinus sp.

Figure 4. Wood rot caused by Phellinus sp.

\section{LOKALITET BR. 5 - CIPROVAC}

Ovo je područje šumske sastojine hrasta crnike i lovora s primjesom jasena, zelenike, tršlje i planike, mjesto okupljanja jelenske divljači. Gotovo svako stablo svih vrsta šumskog drveća oštećeno je djelovanjem divljači te se vide mnoge velike ozljede na kori (slika 5). Na gotovo svakom stablu nalazi se parazitska gljiva Phellinus sp. koja uzrokuje trulež drva a posljedica su prijelomi i propadanje debla i debljih grana. $\mathrm{Na}$ jasenu se vide bušotine kukaca i trulež debla te rakasta zadebljanja od bakterioze. Grupe jasenovih stabala iz panja su vidljivo oštećena od divljači (struganje tijelom i rogovima te guljenjem kore) i zaražena gljivom Phellinus sp. Trulež se često proteže duž cijele visine debla tako da se stabla uslijed krhkosti prelome. Ispod kore stabala vide se hodnici potkornjaka. Tlo je devastirano, humusni sloj je stanjen, korijenje stabala je ogoljelo i podložno je oštećivanju pod kopitima jelenske divljači. Ozljede na korijenju su također ulazna mjesta za štetne gljivične organizme i kukce čijim djelovanjem dolazi do truleži i propadanja stabala. Na deblima starijih stabala hrasta crnike nađene su rakaste tvorevine - bakterioze. 


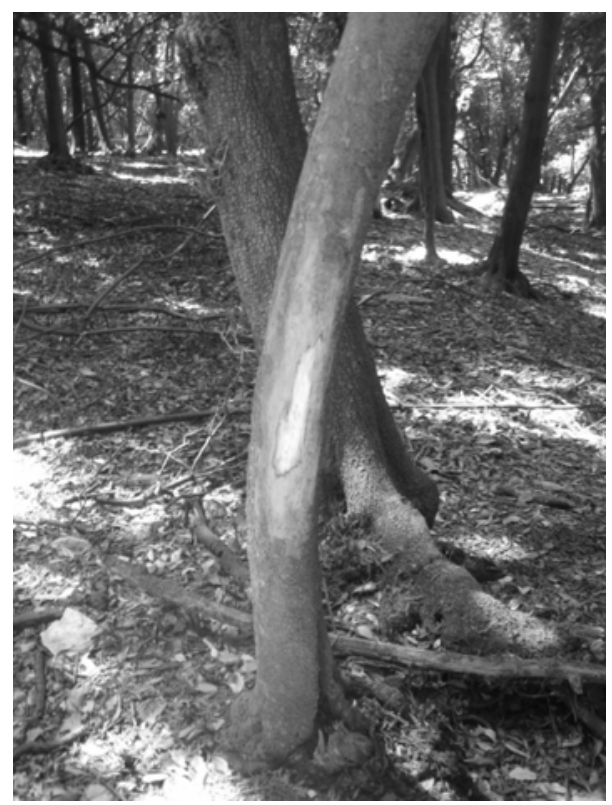

Slika 5. Oštećenje od divljači na lovoru Figure 5. Damage to a laurel tree by game

\section{LOKALITET BR. 6 - CRNIKOVAC}

U šumskoj sastojini prevladava hrast crnika 92\% i lovor $8 \%$. Na mnogim stablima obje vrste drveća prisutne su ozljede od divljači, uzdužne pukotine, gljiva Phellinus sp. na deblu i na debljim granama te jasno vidljiva trulež drva na ozljedama koja se širi u dubinu i visinu stabala. Na lišću obiju vrsta prisutna je zaraza gljivom Phyllosticta quercus ilicis Sacc. malog do srednje jakog intenziteta.

\section{LOKALITET BR. 7 - STARI VINOGRADI}

Pejzaž čine soliterna stabla crnike. Na jednom stablu hrasta crnike prisutna je vrlo jaka zaraza lišća u vidu gala koje uzrokuje grinja Aceria ilicis G. Canestrini. Na stablima su uočena stara i raspadnuta plodišta gljiva truležnica koje nije bilo moguće determinirati. U krošnjama i na deblima mnogih stabala nađena su mlada i stara plodišta gljive Phellinus sp.

\section{LOKALITET BR. 8 - MRTVI VRH}

Grupa starijih i srednjedobnih stabala alepskog bora i brucijskog bora rastu na ovom lokalitetu. Na stablima, na kori i na ogoljelom deblu, uočene su rupice i bušotine kukaca, piljevina i intenzivno smoljenje. Uzročnici su različiti ksilofagni 
kukci: iz porodice Scolytidae: potkornjaci Ips sexdentatus Boern., srčikar Tomicus spp.; iz porodice Buprestidae : krasnik (Phaenopis cyanea F.), iz porodice Curculionidae: pipe (Pissodes spp.), iz porodice Siricidae: osa drvarica Sirex sp.

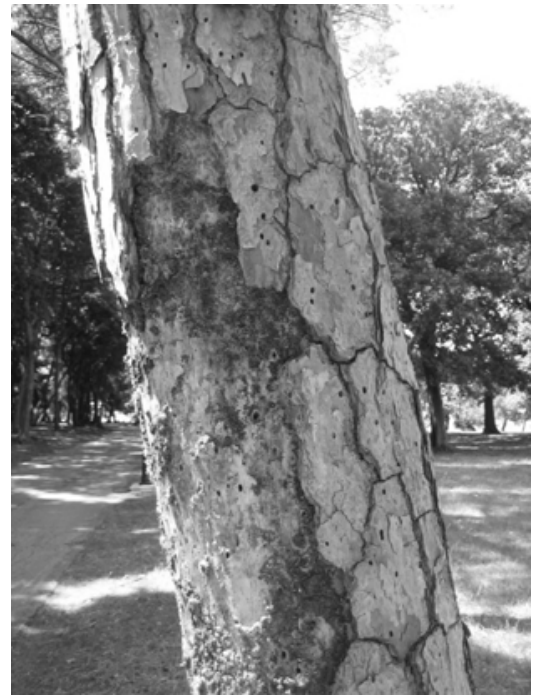

Slika 6. Alepski bor oštećen ksilofagnim kukcima

Figure 6. Damage to the Aleppo pine by insects

U tabeli 2 prikazani su štetni biotički čimbenici prema vrstama drveća.

\begin{tabular}{|c|c|}
\hline Vrsta drveća (Tree species) & $\begin{array}{l}\text { Biotički čimbenici (gljive, kukci, divljač) } \\
\text { Biotic factors (fungi, insects, game) }\end{array}$ \\
\hline \multirow[t]{2}{*}{ Quercus ilex $L$. } & $\begin{array}{l}\text { Gljive } \\
\text { Phellinus sp. } \\
\text { Phyllosticta quercus ilicis Sacc. } \\
\text { Cronartium quercuum (Berk.) Miyabe ex Shirai } \\
\text { Kukci } \\
\text { Coraebus bifasciatus Vilers. } \\
\text { Grinja } \text { Aceria ilicis } \text { G. Canestrini } \\
\text { Oštećenja od divljači }\end{array}$ \\
\hline & Bakterioza \\
\hline $\begin{array}{l}\text { Calocedrus decurens (Torr.) } \\
\text { Florin }\end{array}$ & $\begin{array}{l}\text { Gljive } \\
\text { Cronartium quercuum (Berk.) Miyabe ex Shirai } \\
\text { Kabatina thujae Schneider et von Arx }\end{array}$ \\
\hline Pinus halepensis Mill. & $\begin{array}{l}\text { Gljive } \\
\text { Lophodermium pinastri (Schrad. ex Hook) Chev. } \\
\text { Lophodermium seditiosum Minter, Staly et Millar, } \\
\text { Mycospherella pini } \text { Rostrup ap. Munk } \\
\text { Thyriopsis halepensis (Cooke) Thess. et Syd. }\end{array}$ \\
\hline
\end{tabular}




\begin{tabular}{|c|c|}
\hline & $\begin{array}{l}\text { Kukci } \\
\text { Ips sexdentatus Boern. } \\
\text { Tomcus spp.; } \\
\text { Phaenopis cyanea F. } \\
\text { Pissodes spp. } \\
\text { Sirex sp. } \\
\text { Mravi } \\
\text { Oštećenja od divljači }\end{array}$ \\
\hline Pseudotsuga douglasii (Mirb.) & Kukci \\
\hline Franco. & Aphydidae \\
\hline Cupressus sempervirens L. & $\begin{array}{l}\text { Gljive } \\
\text { Seiridium cardinale (Wagner) Sutton et Gibson } \\
\text { Oštećenja od divljači }\end{array}$ \\
\hline Laurus nobilis L. & $\begin{array}{l}\text { Gljive } \\
\text { Phellinus sp. } \\
\text { Phyllosticta quercus ilicis Sacc. } \\
\text { Oštećenja od divljači }\end{array}$ \\
\hline Fraxinus ornus L. & $\begin{array}{l}\text { Gljive } \\
\text { Phellinus sp. } \\
\text { Kukci } \\
\text { Ips spp. } \\
\text { Sirex sp. } \\
\text { Oštećenja od divljači } \\
\text { Bakterioza }\end{array}$ \\
\hline Phillyrea latifolia $\mathrm{L}$. & $\begin{array}{l}\text { Gljive } \\
\text { Phellinus sp. } \\
\text { Oštećenja od divljači }\end{array}$ \\
\hline Arbutus unedo L. & $\begin{array}{l}\text { Gljive } \\
\text { Phellinus sp. } \\
\text { Oštećenja od divljači }\end{array}$ \\
\hline
\end{tabular}

Tabela 2. Pregled uzročnika bolesti i šteta po vrstama drveća Table 2. List of diseases and insects

Kako bi se smanjile štete i obnovila vegetacija na otoku Veliki Brijun potrebno je provoditi mjere zaštite: orezivanje suhih i zaraženih grana te dijelova krošanja, uklanjanje suhih stabla, premazivanje ozljeda fungicidnom pastom, spaljivanje otpadnog zaraženog biljnog materijala. Potrebno je provoditi redovni monitoring zdravstvenog stanja na terenu $i \mathrm{u}$ skladu $\mathrm{s}$ dobivenim podacima monitoringa provoditi zaštitu šumskog drveća. Sastojine hrasta crnike treba obnoviti i zaštiti. Na otoku treba smanjiti broj divljači i dovesti u ekološku ravnotežu biljni i životinjski svijet. 


\section{ZAKLJUČCI - Conclusions}

Zdravstveno stanje šumske vegetacije na otoku Veliki Brijun je narušeno. Na svih osam lokaliteta (Hotel «Neptun», Borov Vršić, Straža, Planikovac, Ciprovac, Crnikovac, Stari vinogradi i Mrtvi vrh) prisutne su štetne gljive, kukci i oštećenja od divljači. Najveće su štete posljedica oštećenja uslijed prekobrojne visoke divljači i gljive truležnice roda Phellinus. Najoštećenije su sastojine hrasta crnike. Mjerama zaštite i obnove potrebno je staviti pod kontrolu bolesti i štetnike i uspostaviti ekološku ravnotežu biljnog i životinjskog svijeta na otoku.

\section{LITERATURA - Literature}

1. FAtović - FERENČIĆ, S., (2006): Brijuni Archipelago: Story of Kupelwieser, Koch and Cultivation of 14 Islands. Croat Med J. 47:369-71.

2. Glavaš, M. (1999): Gljivične bolesti šumskog drveća, Sveučilište u Zagrebu, Šumarski fakultet Zagreb

3. hartman, G., Nienhaus, F., Butin, H. (2007): Atlas šumskih oštećenja (Dijagnoza bolesti drveća), ITD Gaudeamus d.o.o., Požega

4. Riffle, W. J., Peterson, W. G. (1986): Diseases of trees in the Great plains. USDA Forest Service

5. ZUBRIK, M., KunCA, A., Novotny, J. (2008): Hmyz a huby: Atlas poškodeni lesnych drevin, Narodne lesnicke centrum, Zvolen

6. www.brijuni.com

\section{SUMMARY - Sažetak}

National park Brijuni is archipelago of two larger islands (Veliki Brijun and Mali Brijun) and twelve smaller islands that is located in the northern part of the Adriatic Sea, near the Istria Peninsula. The islands are favorite tourist destination because of the natural beauty of the forest vegetation, picturesque landscape, seacoast and its wildlife. Typical Mediterranean vegetation in National Park Brijuni is forest associations Orno - Quercetum ilicis and its form Orno - Quercetum ilicis laurosum. The health condition of the forest vegetation was observed in eight locations. The disease symptoms were recorded. The samples of the plant material and fungi were collected, brought to the laboratory and analyzed. The preliminary health condition survey showed: leaf spots on Quercus ilex and Laurus nobilis caused by fungus Phyllosticta quercus ilicis Sacc, death of branches and tree tops of Cupressus sempervirens caused by fungus Seiridium cardinale (Wag.) Suton et. Gibson, foliar disease on Pinus halepensis and Pinus brutia caused by fungi Lophodermium pinastri (Schrad. ex Hook) Chev., Lophodermium seditiosum Minter, Staly et Millar, Mycospherella pini Rostrup ap. Munk and Thyriopsis halepensis (Cooke) Thess. et 44 
Syd. and insects in the bark and wood on Pinus halepensis and Pinus brutia like Coraebus bifasciatus Herbst, Ips sexdentatus Boern., Tomcus spp., Phaenopis cyanea F., Pissodes spp., Sirex sp., stem damages caused by game on different tree species and serious damage to forest tree species in Quercus ilex stands caused by fungus Phellinus sp. Forest protection measures should be carried out with purpose to control the diseases and damages and to restore the natural ecological balance among wildlife and vegetation. 